\title{
Los Archivos de Arte: Perspectivas para la distinción
}

Dr. Arturo Valencia Ramos. Departamento de Bellas Artes. Universidad de Sonora. arturo.valencia@unison.mx

Resumen La interpretación de las nociones archivísticas del principio de procedencia y el respeto al orden original resulta fundamental para orientar el sentido de la práctica, sea ésta la organización de acervos documentales con vistas a la constitución de fondos, o bien, su arreglo para crear archivos como obras de arte. El propósito fundamental de este ensayo es abordar esa distinción. Se presenta a partir de tres ejes relacionados: La teoría archivística contemporánea como fundamento de la organización de los acervos documentales; la memoria desde la perspectiva de las teorías de la historia y de los sistemas sociales; $y$, los archivos desde la perspectiva del arte contemporáneo. Se concluye que una vez establecidos los horizontes de observación y los mecanismos de la acción se presentan las condiciones de posibilidad de generar fuentes para la investigación, así como propuestas de experimentación y acción artística.

\begin{abstract}
The interpretation of the principle of origin and the respect to the original order becomes fundamental to guide the sense of the practice, be this the arrangement of the records to constitute document archives, or the arrangement to create archives as works of art. The main purpose of this essay is to addressee that distinction. It comes up henceforth three related axes: the contemporary archivist theory as the foundation to arrange the archives, the memory from the standpoint of the theories of history and the social systems, and the archives from the standpoint of the contemporary art. The conclusion is that once established the horizons for the observation and the mechanisms for the action, the conditions of possibility are presented in order to generate sources for research, as well as proposals for experimentation and artistic action.
\end{abstract}

La posición de los actores sociales frente a los grupos documentales y sus formas de organización, así como ante la recuperación y los usos de la memoria es lo que determina la creación de los archivos. En consecuencia, un grupo documental se constituye en fondo una vez que se le han aplicado los métodos y técnicas archivísticas; sin embargo, una colección de documentos no garantiza la constitución de un fondo. De esta manera, la interpretación de las nociones archivísticas del principio de procedencia y el respeto al orden original resulta fundamental para orientar el sentido de la práctica, sea ésta la organización de acervos documentales con vistas a la constitución de fondos, o bien, su arreglo para crear archivos como obras de arte. El propósito fundamental de este ensayo es abordar esa distinción. El ensayo se presenta a partir de tres ejes relacionados: La teoría archivística contemporánea como fundamento de la organización de los acervos documentales; la memoria desde la perspectiva de las teorías de la historia y de los sistemas 
sociales autopoiéticos; y los archivos desde la perspectiva del arte contemporáneo. El abordaje implica la presentación de las teorías para poder establecer la diferenciación funcional que existe entre los archivos como repositorios de información y resguardo de la memoria y los archivos como objetos de arte. La orientación epistemológica obliga a definir teórica y metodológicamente cada uno de los procesos, por lo que la estrategia de comparación y contraste resulta de gran apoyo. Se concluye que una vez establecidos los horizontes de observación y los mecanismos de la acción se presentan las condiciones de posibilidad de generar fuentes para la investigación, así como propuestas de experimentación y acción artística.

La práctica archivística se ha desarrollado a partir de la emergencia del Estado como estructura funcional de organización social; sin embargo, la teoría archivística moderna se crea con la definición de principios organizativos básicos constituidos para garantizar la ordenación lógica de los documentos y grupos documentales, así como su conservación con fines de consulta y difusión cultural. Los archivos se crean entonces tanto para servir a la administración actual de las instituciones y los particulares, así como soporte para las fuentes de investigación histórica.

En la teoría ha quedado ya muy claro que la archivística es una ciencia que si bien es cierto trata sobre los documentos, su objetivo fundamental son los archivos, entendidos a la vez como los edificios que resguardan los repositorios documentales, así como los fondos que los constituyen. De ahí que las condiciones físicas y climáticas del resguardo sean tan importantes como su organización funcional y orgánica. En resumidas cuentas y a partir de las diferentes definiciones de la archivística podemos concluir que se trata de la ciencia de los archivos cuyos objetos son "la conservación, administración, clasificación, ordenación, interpretación" (Schellenberg, 1987, p. 44) de la documentación archivada. En este sentido, la prioridad de los estudios archivísticos viene dada por los archivos, la documentación y la información.

Al concebir el archivo dentro de un sistema tenemos que remitirnos al principio de procedencia y de respeto al orden original. Este principio implica el respeto a la jerarquía externa de los fondos, implica también no confundirlos con otros aunque pertenezcan a la misma institución y aunque los tipos documentales sean semejantes. Este principio que, según Elio Lodolini "fue aplicado por primera vez en Dinamarca en 1791, con la instrucción de la Comisión para la ordenación de los archivos" (como se cita en Heredia, 1991, p. 33) y con el cual surge la archivística moderna significa que debemos respetar la estructura jerárquica de la entidad que los produjo, sea una institución pública, privada o bien se trate de un particular. Significa que debemos conservar los documentos dentro del fondo documental al que naturalmente pertenecen, por lo que hay que organizarlos, respetando la estructura orgánica del ente productor. Significa, en pocas palabras, que debemos de respetar el orden original. Respetar el orden original significa a su vez que la ordenación interna de un fondo documental debe mantener la estructura que tuvo mientras conservaba sus valores primarios.

A este principio debemos unir la noción del ciclo vital de la documentación, que proviene de la archivística norteamericana de la tercera década del siglo XX y se le adjudica a Brooks (1991, p. 174). Se puede definir como el tiempo de vida de los documentos, desde que se originan como parte de un trámite o función, es decir, cuando están activos, cuando aún conservan sus valores primarios, para 
después pasar por un período durante el cual se concentran y pueden o no ser utilizados en la gestión, hasta que por un proceso de expurgo son seleccionados para desecharse o ser conservados de forma permanente y adquieren valores secundarios, que es cuando son útiles para la investigación. Hasta aquí se dice que los archivos conservan la memoria institucional o la de aquellos que por sus acciones han obtenido un espacio en la historia.

Ahora bien, la memoria entendida en términos sistémicos es a la vez "la facultad de discriminar entre olvidar y recordar" (Luhmann, 2006, p. 90), así como un mecanismo de actualización del recuerdo. Esto significa que tanto las personas como las instituciones y en general lo que entendemos como sociedad requieren de esos mecanismos para poder accionar en el presente y diferenciarse frente a su entorno. Sin embargo, el derecho al olvido también forma parte de ese mecanismo de distinción y selección. La distinción olvidar/recordar implica un acto de selección que en la sociedad es casi siempre un acto político.

Si consideramos este mecanismo desde la perspectiva archivística podemos decir que organizamos la documentación en fondos cuyas características hemos definido a partir de los principios mencionados en los párrafos anteriores. Así, estos fondos resguardan la memoria de forma tal que la información en ellos contenida se utilizará solo cuando sea necesario y no de otra manera. Esto significa que actualizamos el recuerdo a partir de un mecanismo de selección en la memoria. Pero la memoria no es solo un cúmulo de información sino una red de significaciones auto referenciales y recursivas solo necesarias para el mantenimiento del propio sistema y, por tanto, para su distinción frente al entorno.

Como tal, entonces, la selección no se presenta al azar. Digámoslo de otra manera: Normalmente un archivo administrativo es un archivo abierto que sabemos se cerrará cuando concluya el trámite. Los catálogos de disposición documental nos dan cuenta de la temporalidad y vigencia de esa documentación por lo que su vida activa se puede prolongar únicamente los años que determine la normatividad. No es así el caso de los archivos históricos.

Los archivos históricos son, por definición, archivos cerrados y "tienen un fin exclusivamente cultural y científico" (Aréval, 1998, p. 26) . Están constituidos por documentación que ha concluido su vigencia administrativa y obtiene ahora valores secundarios; sin embargo también ahora se convierte en objeto de la memoria histórica...y normalmente esa memoria histórica tiene connotaciones políticas. De ahí que la selección del recuerdo esté condicionada por contingencias que hacen necesaria la significación y/o la re-significación de la información contenida en los documentos de archivo para otorgarle un valor en el presente, pero solo de aquello que es necesario significar. Así, nuevamente realizamos un acto de selección. Entonces, al seleccionar incluimos y excluimos algo. De esta manera la historia está escrita por actos de selección.

Desde la perspectiva de la teoría archivística no existen los archivos de arte propiamente dichos; lo que existen son fondos documentales organizados de tal manera que nos dan cuenta de acontecimientos sociales que por su trascendencia se han convertido en hechos históricos. Pero dada la proclividad política de conceder a las personas un lugar importante en el transcurrir de la vida damos a los fondos el nombre de quienes paulatinamente con el correr de los años los fueron constituyendo; así, por ejemplo, en la Universidad de Sonora tenemos el fondo Emiliana de Zubeldía que contiene documentación valiosa para el campo de la cultura musical; el fondo del poeta Alonso Vidal y recién estamos constituyendo el Fondo del Instituto de Bellas Artes. Cuando decimos que son fondos cerrados nos referimos a que tienen fechas extremas tanto de 
inicio como final por lo que todo aquello que se le incorpore difícilmente rebasará esas fechas.

Los fondos de archivo no son meras colecciones organizadas temática o cronológicamente, sino que responden a formas específicas de organización para lo cual existen cuadros de clasificación que nos permiten ubicar la posición funcional y orgánica de la documentación así como su signatura topográfica; sin embargo, una de las funciones del archivo es la difusión cultural y para ello se vale de la exposición de documentos que resultan significativos en el entorno social. Algunos de los documentos expuestos pueden corresponder al múltiple campo de las artes, pero está fuera de su interés y de toda norma archivística el que con tales exposiciones se estén realizando obras de arte. Dicho de una manera lacónica y tal vez cruel: el hecho de que un archivista organice una exposición con documentos de arte no lo convierte en artista.

En efecto, tal y como lo señala Guasch (2017) "en la génesis de la obra de arte «en tanto que archivo» se halla efectivamente la necesidad de vencer al olvido, a la amnesia mediante la recreación de la memoria misma a través de un interrogatorio a la naturaleza de los recuerdos" (p. 158). Así, esta forma específica de obra de arte está constituida por elementos varios y "todo indicaría que el archivo se ha vuelto un lugar común para las más variadas producciones de arte y uno de los formatos dominantes, o preferidos en las exposiciones contemporáneas" (Tello, 2015 , p. 126). No hemos definido, sin embargo, qué entendemos por archivo de arte sino que damos por hecho su existencia sin la necesidad de definirlo.

Párrafos arriba he señalado que desde la perspectiva archivística los archivos de arte como tales no existen, pero desde la perspectiva del arte se han convertido en una tendencia de forma tal que se habla del "giro archivístico". Desde mi punto de vista se hace importante la ubicación del observador para definir de qué tipo de objeto estamos hablando y por tanto qué tratamiento debemos darle. En principio podemos decir que estamos hablando de objetos diferentes dada la carga comunicativa que le otorgamos a uno y otro. Esto, sin embargo, es confuso porque no especificamos dónde comienza una perspectiva y dónde termina la otra.

La obra de arte "en tanto que archivo" debe tratarse no desde la teoría y práctica archivística sino desde la teoría y práctica de las artes. Solo así podemos dilucidar la carga semántica que porta y el discurso que comunica. Los actores y agentes involucrados son distintos así como el sentido que los conduce. Veámoslo de esta manera: Aludir al principio de procedencia es fundamental en la organización de los archivos, de cualquier archivo; pero acudir a ese principio desde las artes resulta innecesario y hasta confuso ya que no aporta nada a la constitución de la obra de arte "en tanto que archivo". Bajo esa perspectiva y denominación, su fundamento no se encuentra en una tipología documental determinada sino en la distinción recordar/olvidar, que incluso rebasa los argumentos estéticos convencionales. De ahí el peso que se concede al argumento acerca del giro archivístico. Un enfoque plausible en el abordaje de este tema lo propongo desde la Teoría de los Sistemas Sociales.

Por un lado, la archivística se encuentra ubicada dentro del sistema de la ciencia y sus medios de comunicación simbólicamente generalizados son los productos resultado de la organización, entre ellos las guías y los catálogos. De aquí la importancia de la teoría del ciclo de la documentación: los documentos dentro del sistema organizativo, como hemos dicho antes, tienen valores diferentes dependiendo del punto en el que se encuentren en el proceso. Para la ciencia archivística la conservación de la memoria forma parte de sus operaciones por lo que su objeto fundamental es el archivo, pero como estructura administrativa y no como obra de arte. 
Por otro lado, el arte es un sistema social que establece una diferencia frente a su entorno por lo que sus medios de comunicación simbólicamente generalizados son las obras de arte, de cualquier tipo y corriente. En ese entorno se encuentra tanto la ciencia archivística como los archivos en cuanto estructuras organizativas. La memoria resulta un tema en el sistema del arte, pero no es su único tema. Por ello podemos decir que ahí donde la memoria se aborda como fundamento del discurso aparece la obra de arte "en tanto que archivo".

Así, entonces, cuando hablamos de los archivos de arte los podemos abordar como los espacios de interpenetración de dos sistemas diferenciados: la archivística por un lado, y el arte, por otro. El punto de enlace lo encontramos en la memoria (en tanto portadora de información y carga semántica) cuyo tratamiento e interpretación dependerá de la perspectiva de la observación. Ambos sistemas desarrollan su propia clausura operativa e incluyen en esa operación únicamente lo que es necesario. Lo que nosotros observamos, en todo caso, son los resultados de los mecanismos de la distinción inclusión/exclusión que operan en los sistemas y que comunican hacia el entorno.
Por tanto, podemos decir que el archivo es una obra de arte no en tanto resultado de la organización sino de la transfiguración que se presenta al otorgar a la documentación utilizada en la muestra un sentido vindicador de la memoria. Entendemos de esta manera porqué la significación del espacio físico y social no está dado por la estantería y la signatura topográfica, sino por la galería y las hojas de sala que nos explican el contenido de la exposición. Esta también es la razón por la cual las comunidades de discurso se han diferenciado, aunque puedan compartir términos similares - que utilizan de manera equívoca como, por ejemplo, el de "archivo de arte".

Podemos entonces concluir como iniciamos: la posición de los actores sociales frente a los grupos documentales y sus formas de organización, así como ante la recuperación y los usos de la memoria es lo que determina la creación de los archivos. Dado que es en el espacio social donde se determina el discurso hay que especificar cuál es ese espacio y a qué comunidad de discurso pertenece a fin de que la acepción de archivo de arte contenga una denotación (como tal) unívoca y podamos entender cuando la obra de arte se entiende "en tanto archivo".

\section{Referencias}

Arévalo, V. H. (1998). Diccionario de Términos Archivísticos. In. Argentina: Ediciones del Sur.

Guasch, A. M. (2017). Los Lugares de la Memoria: El arte de archivar y recordar. Retrieved from http://www.raco.cat/index.php/Materia/article/viewFile/83233/112454

Heredia, A. (1991). Archivística General. Teoría y práctica. In (5ta. ed.). Sevilla.

Luhmann, N. (2006). La Sociedad de la Sociedad. México: Herder-UIA.

Schellenberg, T. R. (1987). Archivos Modernos. Principios y Técnicas. México: Archivo General de la Nación.

Tello, A. M. (2015). El arte y la subversión del archivo. Aisthesis(58), 125-143. Retrieved from http://www.scielo.cl/scielo.php?script=sci_abstract\&pi$d=S 0718-71812015000200007 \& \operatorname{lng}=e s \& n r m=i s o \& \operatorname{lng}=e s$

http://www.scielo.cl/scielo.php?script=sci_arttext\&pi$\mathrm{d}=$ S0718-71812015000200007\&lng=es\&nrm=iso\&tIng=es

http://www.scielo.cl/pdf/aisthesis/n58/art07.pdf. doi:10.4067/S071871812015000200007 